Article, Review

\title{
Research on Regional Differences and Influencing Factors of Chinese Industrial Green Technology Innovation Efficiency Based on Dagum Gini Coefficient Decomposition
}

\author{
Liyuan Zhang ${ }^{1}$, Pengzhen Liu ${ }^{2, *}$, Heather tarbert ${ }^{1}$, Qingyu Bu ${ }^{3}$ \\ 1 School of Business and Creative Industries, University of the West of Scotland, Paisley PA1 2BE, UK; liyu- \\ an.zhang@uws.ac.uk \\ 2 School of Management, Shandong University of Science and Technology,China; \\ B00357508@studentmail.uws.ac.uk \\ 3 Department of Sociology ,University of Illinois at Urbana-Champaign, Urbana, IL, United States; qing- \\ yub2@Illinois.edu \\ * Correspondence: B00357508@studentmail.uws.ac.uk ;Tel: 0044-7512875613
}

\begin{abstract}
Industrial green technology innovation has become an important content in achieving high-quality economic growth and comprehensively practicing the new development concept in the new era. This paper measures the efficiency of industrial green technology innovation and regional differences based on Chinese provincial panel data from 2005 to 2018, using a combination of the super-efficient SBM model for considering undesirable outputs and the Dagum Gini coefficient method, and discusses and analyses the factors influencing of the industrial green technology innovation efficiency by constructing a spatial econometric model. The results show that: firstly, the industrial green technology innovation efficiency in China shows a relatively stable development trend, going through three stages: " stationary period", " recession period " and "growth period ". However, the efficiency gap between different regions is obvious, specifically in the eastern $>$ central > western regions of China, and the industrial green technology efficiency innovation in the central and western regions is lower than the national average. Secondly, regional differences in the efficiency of industrial green technology innovation in China are evident but tend to narrow overall, with the main reason for the overall difference being regional differences. In terms of intra-regional variation, variation within the eastern region is relatively stable, variation within the central region is relatively low and shows an inverted 'U' shaped trend, and variation within the western region is high and shows a fluctuating downward trend. Thirdly, the firm size, government support, openness to the outside world, environmental regulations and education levels contribute to the efficiency of industrial green technology innovation. In addition, the industrial structure hinders the efficiency of industrial green technology innovation, and each influencing factor has different degrees of spatial spillover effects.
\end{abstract}

Keywords: Industrial green technology innovation efficiency; Dagum Gini coefficient; spatial econometrics; Regional differences

\section{Introduction}

As the "baton" to guide the construction of ecological civilization and green economic development, the new development concept not only makes higher requirements for the current economic structure adjustment and industrial transformation and upgrading, but also adds value to green technology innovation (GTI), the primary driving force to promote the development of green and light industry. As the main battlefield of green innovation development and an important starting point of technological innovation driven strategy, the industrial industry is an important engine to promote efficient 
and stable economic growth, and plays an important role in improving the national comprehensive competitiveness[1] . In addition, China is a big industrial country, and industry is an important source of GDP growth, the main battlefield of green innovation and development, an important starting point of technology innovation driving strategy, and an important engine for promoting efficient and stable economic growth[ㄹ]

In recent years, China's scientific and technological research and development (R\&D) achievements have made major breakthroughs, and the industry has been booming. However, due to the influence of geographical location and historical problems, the imbalance of regional development in the process of innovation has become increasingly prominent, such as the increase of environmental additional cost in the eastern part of China, the low achievement transformation efficiency of in the central part of China and the ecological economic imbalance in the western part, which has seriously hindered the development of industrial GTI to high quality and deep level[]ㅡ. At the same time, due to the obvious "gradient difference" in the economic and social development of the eastern, central and western regions of China, it is difficult to implement the transformation of old and new kinetic energy and the innovation of new and old industries, and the obstruction of technology exchange and knowledge dissemination is not conducive to the improvement of the level of GTI. In a word, how to comprehensively improve the industrial green technology innovation(GTI) efficiency(GTIE) has become an inevitable choice to promote economic transformation and implement. Therefore, scientifically measure the efficiency of China's industrial GTI to explore the key factors and spatial spillover affecting the of industrial GTIE which provides reference theoretical opinions for improving the level of industrial GTI and realizing the high-quality development of China's economy.

To sum up, previous scholars have conducted fruitful research on GTI, but there is still much room for expansion. Firstly, although the existing research can combine the innovation theory with the environmental concept in the construction of the evaluation system, it ignores the promotion of ecological benefits and policy guidance. In addition, the selection of indicators is too simple to reflect the real level of industrial GTIE. Secondly, previous studies emphasized the industrial GTI and its influencing factors at the country level, ignoring the impact mechanism of driving factors on specific regions, such as China's east, middle and west regions and different degrees of spatial spillover effects.

Based on the above, in this paper, intellectual property rights, the number of protection projects and environmental protection applications are included in the evaluation index system as policy input indicators, uses the super-efficiency SBM model considering unexpected output to measure the efficiency of industrial GTI, and tries to answer the following questions combined with Dagum Gini coefficient and spatial econometric model.

\section{Literature review}

Green innovation was first put forward in 1996[4]], and it attracted wide attention. "Dual externality" is a typical feature of green innovation, that is, the positive externality of innovation results coexists with the positive externality of environmental benefits[]․ Early scholars focused on the research of green innovation from a narrow technical perspective, but with the deepening of research, the meaning of green innovation has been greatly broadened, sometimes called ecological innovation, environmental innovation and sustainable innovation[6]. GTI is the core component of green innovation, and the concept of green technological innovation has not yet formed a unified conclusion in the academic circles. Some scholars believe that GTI can effectively reduce product costs from the perspective of product life cycle[7], which is reflected in the whole process from production to promotion and it is finally marketized. From the perspective of enterprises, some scholars believe that GTI mainly includes two aspects: green product technology R\&D and clean energy production technology innovation, which is the main 
way for enterprises to enhance their core competitiveness. From the perspective of overall cost, some scholars think that the core goal of GTI is to minimize the internal and external comprehensive cost in the product life cycle, also known as ecological technology innovation.

Generally speaking, green technological innovation is a comprehensive concept. At present, it is recognized in the academic circles that any creative behavior conducive to realizing the win-win of economy and environment or the harmonious development of "economy, resources and environment" can be called green technological innovation[]. As the main body of GTI activities, industry plays an important role in science and technology R\&D and achievement transformation etc. Therefore, it is of great practical significance to guide industrial enterprises to vigorously carry out GTI activities and improve the GTIE to realize the harmonious coexistence of ecological environment and economic development.

At present, the research topics on the GTIE mainly focus on efficiency measurement[]], evaluation system construction[10], spatial-temporal characteristics[11], influencing factor analysis[12], etc. BCC $[\underline{13}]$ and CCR models[14] are usually used to measure the GTIE in the early stage. However, the traditional DEA model ignores the "relaxation" of factors, resulting in the lack of authenticity of the measurement results. In order to solve this problem, Feng [15] introduced DEA-SBM model to calculate the green innovation efficiency of eight economic zones in China, and compared it with DEA-CCR model to draw a more scientific conclusion of SBM model. With the deepening of research, the super efficiency SBM model not only solves the problem that the traditional DEA model ignores the unexpected output, but also can more refine the efficiency difference of effective units, and has gradually become the mainstream method for measuring the efficiency of green innovation at this stage[16]. The green technological innovation efficiency evaluation system is a comprehensive evaluation method that includes scientific and technological innovation, resource consumption and environmental pollution. It can effectively measure the green level of innovative activities in the economy. It has evolved from the combination of green total factor productivity and technological innovation efficiency. At the same time, it solves the problems that the former does not consider the R\&D input and output, while the latter ignores the influence of resource consumption and environmental pollution on innovation system[17].

At present, most scholars consider the construction of evaluation system of GTI from three aspects: input, expected output and unexpected output. Among them, the input element is mostly selected from labor, capital and energy[18], the expected output mainly includes economic output and technical output[19], and the unexpected output mainly selects industrial three wastes as the measurement index[20]. The research scale of GTIE mainly includes three levels: firm, industry and region[21], which has experienced the evolution from micro level to macro level. In the initial stage of GTI, previous scholars have done rich research on the GTI mechanism and influencing factors at micro company level, and pointed out that incentive policies and capabilities have significant positive effects on the of corporate GTIE. However, with the development of society, some scholars gradually realized that the improvement effect brought by the research at the micro level had great limitations, and then gradually extended the research area to the macro fields such as provinces[22] and the whole country[23], and made a detailed explanation on the temporal and spatial characteristics and evolution law of GTIE in different regions. As a typical index with both economic and ecological characteristics, the green technology efficiency innovation is influenced by many factors, mainly focusing on the analysis of influencing factors such as firm size[24], economic development level[25], environmental regulation[26], industrial structure[27] and educational level[28]. The influence mechanism can be roughly divided into three categories: linear[29], nonlinear[30] and threshold effect[31]. Because of different research fields and methods, the research conclusions are different. 


\section{Research methods and index selection}

\subsection{Index selection}

\subsubsection{Input indicator}

Regarding the input indicators for industrial GTI, four choices were made in terms of manpower, capital, resources and government policies [32].

For manpower input, it is usually expressed by the total number of R\&D personnel or the full-time equivalent of R\&D personnel [33]. Since both the total employed labor force and the actual hours worked have an impact on industrial GTI activities, the full-time equivalent of R\&D personnel was chosen to represent the manpower input level.

For capital investment, previous research mostly used R\&D internal expenditure to express it [34], but this expression method does not accurately reflect the accumulation effect and lag effect of capital investment on industrial GTI. Therefore, the perpetual inventory method was used to calculate the R\&D internal expenditure of provinces and cities, which represents the capital investment [35].

For resource input, three typical indicators are chosen to represent the total amount of industrial water, construction land and industrial energy consumption. The first two indicators reflect the input level of natural resources in green innovation, and the total amount of construction land can also reflect the effect of regional spatial structure optimization. In addition, total industrial energy consumption was chosen mainly because of the greater contribution of enterprises as innovation agents in innovation activities.

For policy input, previous studies have not taken this indicator into account when measuring the industrial GTIE. But in fact government support is also a key factor in determining the level of industrial GTI. However, as the main body of resource consumption and innovation activities, industrial enterprises make decisions under policy incentives, and the output speed and environmental performance of innovation achievements will be affected by policy promulgation. Therefore, based on the research results of Yuting[36], the number of intellectual property protection projects and the environmental protection applications are taken as indicators to measure policy investment.

\subsubsection{Output indicators}

With regard to the output elements of industrial GTI, three perspectives were chosen: economic output, technical output and undesired output.

For economic output, it is usually expressed by economic aggregate or sales revenue of new products. However, given that new product sales revenue is more reflective of the ability to capture profits from the level of innovation in each province and region.

For technological output, scholars have generally choosen the amount of patent applications granted or the patent applications to represent. However, due to the uneven quality of the total number patent applications, it is difficult to reflect the difference of innovation benefits, so this paper chooses the authorized amount of patent application to represent technological output.

For undesired output, previous studies usually used the industrial "three wastes" emissions, mainly including industrial SO2 emissions, industrial smoke (powder) dust emissions, industrial wastewater emissions and industrial solid waste emissions. In addition, considering that the implementation of environmental protection policies may have an obvious effect on environmental improvement, this paper also includes the number of environmental complaints into the unexpected output.

\subsubsection{Influence factor}

Referring to the research results of Qiongwen [37] and Medeiros[38], and taking into account the current situation and characteristics of the development of industrial GTI 
in China, the key factors affecting the efficiency of industrial GTI can be found in the market environment and the regional innovation environment (policy environment). Among them, the influencing factors of market environment mainly include enterprise scale, industrial structure, openness to the outside world and so on. The influencing factors of policy environment mainly include government support, environmental regulation and education level. The following is an explanation of each variable.

Enterprise scale (ES). There are mainly two views on the impact of enterprise scale on industrial GTI: one view holds that the larger the enterprise scale, the more scale returns can be obtained, which is more conducive to GTI, that is, enterprise scale is positively correlated with GTI. Another view is that large-scale enterprises may reduce the industrial GTIE due to more levels, solidified operation system and strong dependence on resources. This paper select the industrial GDP / number of enterprises of each province and city to represent the enterprise scale.

Industrial structure (INS). The undesired output of the green technology innovation(GTI) system(GTIS) is influenced by the industrial structure, so the proportion of the secondary sector is selected to represent the industrial structure.

Openness (OPEN). It is generally believed that the degree of openness to the outside world is positively correlated with the industrial GTIE. Regions with a high degree of opening up are more closely connected with the outside world, which can bring innovative elements such as advanced production technology, high-quality labor force and high-level management experience, which is conducive to enterprises to make up for their own shortcomings in combination with local advantages. This paper selects the total import and export volume to represent the degree of openness to the outside world.

Government support (GOVE). As the manager of the market, the government is the basic guarantee for enterprises to carry out innovation activities. Appropriate support can stimulate the innovation vitality of enterprises and promote the improvement of industrial GTI. However, excessive government support reduce the enthusiasm of enterprise for innovation, make them dependent on preferential policies such as innovation subsidies and green loans, and hinder GTI. Therefore, this paper selects the financial expenditure of government science and technology activities to express the degree of government support.

Environmental regulation (ER). "Porter Hypothesis" holds that appropriate environmental regulation can promote GTI and effectively reduce unexpected output[39], but high-intensity environmental regulation cause enterprises to produce "environmental compliance cost" and occupy the funds originally used for GTI. Therefor, this paper choose the investment amount of industrial pollution control to represent environmental regulation.

Education level (STU). The level of education has an impact on the manpower input indicator of the GTIS, and the level of high-quality labor force is a guarantee for the development of GTIE. Therefore, this paper selects the number of university students to express the education level.

\subsection{Model selection}

\subsubsection{A super efficient SBM model considering undesired}

Compared with the traditional CCR and BCC models, the super efficiency SBM model can incorporate the relaxation variables into the objective function, so as to solve the problem of variable relaxation. At the same time, it can further decompose the effective units with efficiency value of 1 , realize mutual comparison between effective units, and improve the accuracy of calculation results. The specific objective equation model is as follows: 


$$
\begin{aligned}
& \min \rho=\frac{\frac{1}{m} \sum_{i=1}^{m}\left(\bar{x} / x_{i k}\right)}{\frac{1}{r_{1}+r_{2}}\left(\sum_{s=1}^{r_{1}} \overline{y^{d}} / y_{s k}^{d}+\sum_{q=1}^{r_{2}} \overline{y^{u}} / y_{q k}^{u}\right)} \\
& \begin{cases}\bar{x} \geq \sum_{j=1, \neq k}^{n} x_{i j} \lambda_{j}, & j=1,2, \ldots, m \\
\overline{y^{d}} \leq \sum_{j=1, \neq k}^{n} y_{s j}^{d} \lambda_{j}, & s=1,2, \ldots, r_{1} \\
\overline{y^{u}} \geq \sum_{j=1, \neq k}^{n} y_{q j}^{u} \lambda_{j}, & q=1,2, \ldots, r_{2} \\
\lambda_{j} \geq 0, & j=1,2, \ldots, n ; j \neq 0 \\
\bar{x} \geq x_{k}, & k=1,2, \ldots, m \\
\overline{y^{d}} \leq y_{k}^{d}, & d=1,2, \ldots, r_{1} \\
\overline{y^{u}} \geq y_{k}^{u}, & u=1,2, \ldots, r_{2}\end{cases}
\end{aligned}
$$

In equation (1), $\rho$ represents the value of industrial GTIE, $n$ is 30 provinces and cities, $m$ is the number of input indicators. $r_{1}$ and $r_{2}$ represent the number of expected outputs and unexpected outputs respectively. $x, y^{d}$ and $y^{u}$ represent the elements in the corresponding input matrix, expected output matrix and unexpected output matrix.

\subsubsection{Dagum Gini coefficient decomposition method}

The methods to measure regional differences include Theil index, coefficient of variation, Gini coefficient, etc., but these methods can not further decompose the regional gap and compare the distribution of sub samples, so they have some limitations. However, the Dagum Gini coefficient method can decompose the study area into several sub-areas, and calculate the overall difference, intra-regional difference, inter-regional difference and supervariable density respectively, which effectively solves the above problems. Referring to Robert [므], the specific calculation equation of Dagum Gini coefficient method is as follows:

$$
G=\frac{\sum_{j=1}^{k} \sum_{h=1}^{k} \sum_{i=1}^{n_{j}} \sum_{r=1}^{n_{h}}\left|x_{j i}-x_{h r}\right|}{2 n^{2} \bar{x}}
$$

In equation (2), where $G$ represents Dagum Gini coefficient, $n$ represents 30 provinces and cities in China, and $k$ represents the number of sub-regions in the sample. $x_{j i}$ and $x_{h r}$ represent the industrial GTIE values of sub regions $j$ and $h$ respectively, $n_{j}$ and $n_{h}$ represent the number of provinces and cities in sub regions $j$ and $h$ respectively, and $\mathrm{X}$ represents the average value of industrial GTIE in the sample.

Among them, the Dagum Gini coefficient $(G)$ can be decomposed into three parts: intra-regional difference $\left(G_{w}\right)$, inter-regional super variable net value difference $\left(G_{n b}\right)$ and inter-regional transvariation intensity $\left(G_{t}\right)$. See equation(3): 


$$
G=G_{w}+G_{n b}+G_{t}
$$

The specific calculation equation is:

$$
\begin{gathered}
G_{j j}=\frac{\frac{1}{2 \bar{x}_{j}} \sum_{i=1}^{n_{j}} \sum_{r=1}^{n_{j}}\left|x_{j i}-x_{j r}\right|}{n_{j}^{2}} \\
G_{w}=\sum_{j=1}^{k} G_{j j} p_{j} s_{j} \\
G_{j h}=\frac{\sum_{i=1}^{n_{j}} \sum_{r=1}^{n_{h}}\left|x_{j i}-x_{h r}\right|}{n_{j} n_{h}\left(\bar{x}_{j}+\bar{x}_{h}\right)} \\
G_{n b}=\sum_{j=2}^{k} \sum_{h=1}^{j-1} G_{j h}\left(p_{j} s_{h}+p_{h} s_{j}\right) D_{j h} \\
G_{t}=\sum_{j=2}^{k} \sum_{h=1}^{j-1} G_{j h}\left(p_{j} s_{h}+p_{h} s_{j}\right)\left(1-D_{j h}\right) \\
p_{j h}=\int_{0}^{\infty} d F_{h}(x) \int_{0}^{x}(x-y) d F_{j}(y) \\
d_{j h}=\int_{0}^{\infty} d F_{j}(x) \int_{0}^{x}(x-y) d F_{h}(y) \\
d_{j h}-p_{j h}+p_{j h}
\end{gathered}
$$

In equation (3-11), $G_{j j}, G_{w}, G_{j h}, G_{n b}$ and $G_{t}$ represent Gini coefficient in region $j$, the internal difference of region $j$, the coefficient of variation between region $j$ and region $h$, the difference between region $j$ and region $h$ and transvariation intensity respectively. $p_{j}$ represents the proportion of the number of samples in area $j$ in the total number of samples. $D_{j h}$ represents the relative impact of industrial GTIE between region $j$ and region $h$. $D_{j h}$ represents the mathematical expectation of the cumulative summation of industrial GTIE satisfying $x_{j i}>x_{h r}$ in region $j$ and region $h . p_{j h}$ represents the mathematical expectation of the cumulative summation of industrial GTIE satisfying $x_{j i}<x_{h r}$ in region $j$ and region $h . F_{j}$ and $F_{h}$ represent the cumulative density distribution functions of region $j$ and region $h$.

\subsubsection{Spatial econometric model}

Spatial weight matrix. At present, there is no unified standard for setting the spatial weight matrix in academic circles. This paper refers to the research results of Lesage[41], follows the principle of simplification of spatial weight, and gives priority to the adjacent weight matrix $(W)$ composed of only 0 and 1 . The equation is: if $i$ province is adjacent to $j$ Province, the weight $w_{i j}=1$, otherwise $w_{i j}=0$. In addition, the robustness of the 
regression results is tested by constructing the inverse distance spatial weight matrix $(D)$ and the economic distance spatial weight matrix $(E)$.

Spatial econometric model. The commonly used models in previous studies mainly include spatial autoregressive model (SAR), spatial error model (SEM) and spatial Dubin model (SDM). Because the spatial Dubin model(SDM) considers the spatial correlation of dependent variables and independent variables together and has stronger interpretation ability, this paper takes SDM as the starting point of econometric model analysis. Its general form is as follows:

$$
\ln E f f_{i, t}=\rho W \ln E f f f_{j, t}+\gamma_{i} W X_{i, t}+\beta_{i} X_{i}+\mu_{t}+\eta_{i}+\varepsilon_{i, t}
$$

Based on the theoretical model derivation, the empirical model of this paper is:

$$
\begin{aligned}
& \ln E f f_{i, t}=\rho W \ln E f f_{j, t}+\gamma_{1} W \ln E S+\gamma_{2} W \ln I N S+\gamma_{3} W \ln O P E N \\
& +\gamma_{4} W \ln G O V E+\gamma_{5} W \ln E R+\gamma_{6} W \ln S T U+\beta_{1} \ln E S+\beta_{2} \ln I N S \\
& +\beta_{3} \ln O P E N+\beta_{4} \ln G O V E+\beta_{5} \ln E R+\beta_{6} \ln S T U+\mu_{t}+\eta_{i}+\varepsilon_{i, t}
\end{aligned}
$$

In equation (13), where $\rho$ represents the coefficient of spatial lag term, $\gamma_{i}$ is the spatial autoregressive coefficient of explanatory variable, $\mu_{t}$ and $\eta_{i}$ represents individual fixed effect and time fixed effect respectively. $\varepsilon_{i, t}$ is random interference term.

\subsection{Data sources}

The sample selects the data of 30 provinces (cities and autonomous regions) in China from 2005 to 2018. Considering the availability and authenticity of the data, the sample does not include Tibet Autonomous Region, Hong Kong, Macao and Taiwan. The index data are from China Statistical Yearbook, China Environmental Statistical Yearbook, China Patent statistical annual report, provincial and municipal statistical yearbooks and EPS database over the years. The missing data of the year is supplemented by interpolation method.

\section{Regional differences and decomposition of industrial green technology innovation efficiency(GTIE)}

Calculate the industrial GTIE of 30 provinces and cities according to equation (1). With reference to the standards of the National Bureau of Statistics and combined with factors such as economic development level and geographical location, China is divided into three regions: east, middle and west. Among them, the eastern region includes 11 provinces (cities) including Beijing, Tianjin, Hebei, Liaoning, Shanghai, Jiangsu, Zhejiang, Fujian, Shandong, Guangdong and Hainan. The central region includes 8 provinces: Shanxi, Jilin, Heilongjiang, Anhui, Jiangxi, Henan, Hubei and Hunan. The western region includes 11 provinces (cities and autonomous regions) including inner Mongolia, Guangxi, Chongqing, Sichuan, Guizhou, Yunnan, Shaanxi, Gansu, Qinghai, Ningxia and Xinjiang.

The results show that the industrial GTIE shows a trend of "first decline and then increase" (Figure 1): the period from 2005 to 2007 is a stable period, during which the efficiency of industrial green technology innovation always fluctuates around 0.60. In 2009, the industrial GTIE showed a "cliff-like" decline, which indicated that the balance between China's industrial innovation output and economic development was broken, and the influence of external factors on industrial development was enhanced. The main reason was that the global financial crisis seriously affected the further marketization of industrial technology innovation achievements, the import and export trade of new 
products was greatly impacted, and the economic benefits of various regions declined to varying degrees, which led to a substantial decline in the industrial GTIE. After 2010, the industrial GTIE began to pick up, and the curve changes gradually stabilized.

In terms of regions, the industrial GTIE in the eastern region is the highest, showing a fluctuating upward trend from 2010 to 2018, with gentle curve change and relatively stable development. The industrial GTIE in the central and western regions has always been lower than the national average. It began to rise gradually after the financial crisis, especially after 2013. This change also caused the fluctuation of the national average to rise. The reason is that the environmental protection policies vigorously implemented in the central and western regions have effectively promoted the improvement of industrial green technology innovation efficiency, and the implementation of the "blue sky protection plan" has further clarified that it is an inevitable way for green sustainable development to go hand in hand with the "high beauty" of the ecological environment and the "high quality" of economic development. With the implementation of China's "Western Development Strategy", "4 trillion plan" and "the belt and road initiative" initiative, the investment in industrial infrastructure, traditional technological transformation and scientific and technological R\&D in the central and western regions has been continuously increased, resulting in different degrees of improvement in economic benefits and innovation output of enterprises, and further promoting the industrial GTIE. In addition, the change rule of industrial GTIE in the China's eastern, central and western regions is similar to that of the whole country, but there is an obvious gap among the three regions is obvious, with the highest in the eastern region, the second in the central region and the lowest in the western region. Moreover, the average level of industrial GTIE in the central and western regions is low, which has great room for improvement and potential.

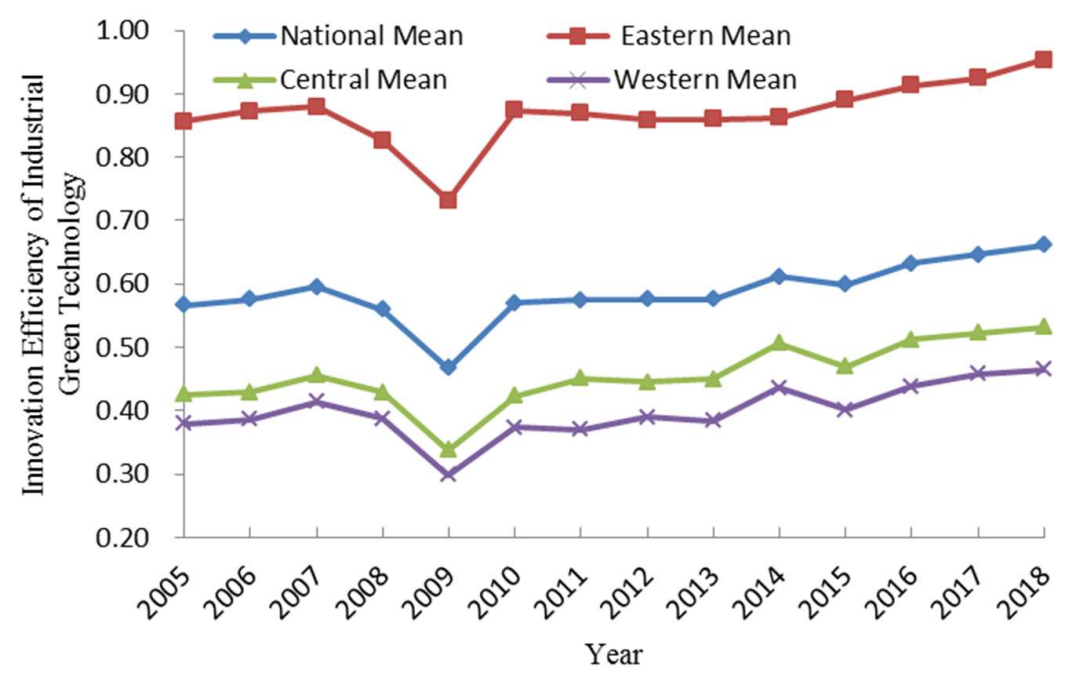

Figure 1 Industrial green technology innovation efficiency(GTIE) from 2005 to 2018

In order to further reveal the regional differences and sources of China's industrial green technology innovation efficiency, based on the panel data of 30 provinces and cities, this paper uses Dagum Gini coefficient decomposition method to measure the overall differences, regional differences and intra-regional differences of industrial green technology innovation efficiency from 2005 to 2018. The results are shown in Table 1.

In terms of the overall difference, during the investigation, the overall Gini coefficient of industrial GTIE fluctuated and decreased, and the lagging area of technical effi- 
ciency gradually formed a "catch-up effect" on the leading area. From 2005 to 2009, the overall gap fluctuated repeatedly, and the fluctuation range was large, from 0.286 in 2005 to 0.272 in 2007, and then rose to the peak of 0.406 . Since then, the overall Gini coefficient continued to decline until there was a small "rebound" in 2013. From 2014 to 2018, the Gini coefficient showed a trend of "rise-decline-rise" and repeated jumps, reaching the lowest value of 0.242 in 2016. This change shows that the overall synergy of China's industrial GTI is weak, and there are great differences in regional development. However, with the implementation of the sustainable development strategy and the introduction of a series of environmental protection policies, industrial enterprises have been greatly promoted to gradually change from the "three high and one low" production mode to the "resource-saving and environment-friendly" development mode, The unbalanced efficiency of industrial GTI has been alleviated slightly.

In terms of intra-regional differences, the regional differences of industrial GTIE in the western region are the highest, followed by the eastern region and the central region. Specifically, the Gini coefficient in the eastern region changes gently, always floating up and down at 0.2 , which is due to the close technical exchange, excellent development environment, strong industrial foundation, coordinated development strategy and inclusive national policy in the eastern region. The Gini coefficient in the central region shows an inverted "U" trend, with a large fluctuation range and an obvious downward trend, rising from 0.099 in 2005 to 0.156 in 2013, and then began to fluctuate and decline. This shows that after the country put forward the sustainable development strategy, the central region has experienced a period of upgrading the industrial structure, and enterprises have narrowed the gap in the industrial GTIE by accelerating the elimination of backward production capacity and promoting technological innovation. The Gini coefficient in the western region is not stable, showing a "wave-like" trend of repeated changes, but the overall difference within the region is decreasing. The reason may be that the implementation of the strategy of developing the western region, the country's strong support for the infrastructure construction in the western region and the encouragement of the eastern enterprises to move westward have made the western region have economic foundation and technical support, and the industrial GTIE has also been improved, and the imbalance of industrial GTIE in the western region has been obviously alleviated.

In terms of inter-regional differences, the overall difference in the efficiency of industrial green technology innovation between regions shows a fluctuating downward trend, with the largest difference between East-West regions, followed by East-Central regions, and the smallest difference between Central-West and much smaller than the difference between East-West and East-Central regions. This suggests that the differences between the eastern region and the central and western regions are a major factor in the uneven industrial GTIE. Specifically, the difference between the East and Central regions was always between 0.291 and 0.478 , and reached a peak in 2009, after which it began to fluctuate downwards, with a greater fluctuation from 2013 to 2016, and reached a minimum value in 2016. The difference between the east and west regions is slightly higher than that between the east and central regions, with an inverted " $N$ " shape trend, which indicates that the synergy of industrial green technology innovation between the two regions is the weakest. The gap between the central and western regions is smaller and does not fluctuate much.

In terms of contribution rate, inter-regional $(\mathrm{Gnb})$ contribution indicates the difference in industrial GTIE inter-regions. The intra-regional $\left(\mathrm{G}_{w}\right)$ contribution represents the difference in industrial GTIE among provinces and cities in the east, central and western regions. The transvariation intensity (Gt) represents the cross impact on the industrial GTIE. During the investigation period, the inter-regional contribution rate accounted for about $60 \%$, which was the main factor causing the efficiency gap of China's industrial GTI, followed by the intra-regional contribution rate, accounting for about $25 \%$, and the influence of super variable density was the least, accounting for about $15 \%$. From the 
change trend, Gnb shows a fluctuating downward trend as a whole. From 2012 to 2018, it shows the characteristics of wavy-like change, with a decrease of $5.97 \%$ compared with 2005. Gw is relatively stable and the overall change range is small, Gt increased from $13.906 \%$ in 2005 to $16.616 \%$ in 2008 , but it fell "cliff like" in 2009, reaching the lowest value of $10.673 \%$. After that, it began to recover gradually and reached the peak of $18.288 \%$ in 2017. Therefore, how to effectively narrow the regional differences has become the key to improve the China's industrial GTIE.

Table 1 Gini coefficient decomposition results of China's green technology innovation efficiency(GTIE)

\begin{tabular}{|c|c|c|c|c|c|c|c|c|c|c|}
\hline \multirow[b]{2}{*}{ Year } & \multirow[b]{2}{*}{ Overall } & \multicolumn{3}{|c|}{ Intra-regional differences } & \multicolumn{3}{|c|}{ Inter-regional differences } & \multicolumn{3}{|c|}{ Contribution rate(\%) } \\
\hline & & East & Central & West & $\begin{array}{l}\text { East- } \\
\text { central }\end{array}$ & $\begin{array}{l}\text { East- } \\
\text { west }\end{array}$ & $\begin{array}{l}\text { west - } \\
\text { central }\end{array}$ & $\begin{array}{l}\text { Intra-regional } \\
\text { disparity } \mathrm{G}_{w}\end{array}$ & $\begin{array}{l}\text { Inter-regional } \\
\qquad \mathrm{Gnb}_{\mathrm{nb}}\end{array}$ & $\begin{array}{c}\text { Transvariation } \\
\text { intensity Gt }\end{array}$ \\
\hline 2005 & 0.286 & 0.200 & 0.099 & 0.226 & 0.357 & 0.391 & 0.191 & 23.260 & 62.834 & 13.906 \\
\hline 2006 & 0.287 & 0.198 & 0.099 & 0.222 & 0.370 & 0.388 & 0.185 & 23.039 & 63.128 & 13.833 \\
\hline 2007 & 0.272 & 0.198 & 0.100 & 0.213 & 0.344 & 0.365 & 0.177 & 23.916 & 60.809 & 15.276 \\
\hline 2008 & 0.283 & 0.224 & 0.124 & 0.225 & 0.342 & 0.367 & 0.200 & 25.636 & 57.748 & 16.616 \\
\hline 2009 & 0.406 & 0.309 & 0.143 & 0.286 & 0.478 & 0.549 & 0.267 & 24.215 & 65.112 & 10.673 \\
\hline 2010 & 0.293 & 0.201 & 0.136 & 0.223 & 0.356 & 0.403 & 0.202 & 23.304 & 63.982 & 12.714 \\
\hline 2011 & 0.291 & 0.200 & 0.115 & 0.272 & 0.324 & 0.401 & 0.230 & 24.262 & 61.593 & 14.145 \\
\hline 2012 & 0.286 & 0.209 & 0.105 & 0.260 & 0.315 & 0.391 & 0.230 & 24.683 & 59.732 & 15.585 \\
\hline 2013 & 0.302 & 0.221 & 0.156 & 0.271 & 0.359 & 0.386 & 0.229 & 25.834 & 55.908 & 18.258 \\
\hline 2014 & 0.264 & 0.197 & 0.099 & 0.238 & 0.302 & 0.354 & 0.203 & 25.134 & 57.970 & 16.896 \\
\hline 2015 & 0.267 & 0.201 & 0.101 & 0.239 & 0.323 & 0.347 & 0.197 & 25.499 & 56.389 & 18.112 \\
\hline 2016 & 0.249 & 0.199 & 0.089 & 0.209 & 0.291 & 0.335 & 0.176 & 25.456 & 58.462 & 16.083 \\
\hline 2017 & 0.242 & 0.190 & 0.082 & 0.211 & 0.292 & 0.321 & 0.170 & 25.387 & 56.325 & 18.288 \\
\hline 2018 & 0.248 & 0.196 & 0.070 & 0.201 & 0.306 & 0.335 & 0.163 & 24.623 & 59.076 & 16.301 \\
\hline
\end{tabular}

\section{Analysis on Influencing Factors of industrial green technology innovation efficiency}

\subsection{Analysis of regression results at the national level}

Before the spatial econometric model regression, this paper uses Moran's I index to test the spatial agglomeration characteristics of China's industrial GTIE based on the adjacent spatial weight matrix. The results are shown in Table 2. During the investigation period, the Moran's I index of industrial GTIE fluctuated between 0.060 and 0.115 , and all passed the significance test at the $1 \%$ level. Therefore, it can be determined that there is a positive spatial dependence between industrial GTIE of provinces and cities. In addition, by analyzing the temporal change of Moran's I value from 2005 to 2018, it can be seen that its index value shows an " $n$ " trend of first increasing, then decreasing and increasing, indicating that the spatial agglomeration of China's industrial GTIE has experienced a "rise decline rise" process, and its positive spatial correlation has gradually strengthened after 2010. This is consistent with the previous demonstration results. The reason is that the subprime mortgage crisis has shaken the financial system, and the input and output of innovative capital have decreased significantly. However, with the recovery of capital and the rapid improvement of industrial GTIE, the gap between the eastern region and the central and Western regions has become more and more obvious. 
Table 2 Moran's I of industrial green technology innovation efficiency(GTIE) in China

\begin{tabular}{cccccc}
\hline Year & Moran's I & P value & Year & Moran's I & P value \\
\hline 2005 & 0.065 & 0.007 & 2012 & 0.091 & 0.003 \\
2006 & 0.068 & 0.006 & 2013 & 0.102 & 0.003 \\
2007 & 0.075 & 0.005 & 2014 & 0.098 & 0.001 \\
2008 & 0.060 & 0.005 & 2015 & 0.105 & 0.000 \\
2009 & 0.066 & 0.008 & 2016 & 0.113 & 0.002 \\
2010 & 0.075 & 0.001 & 2017 & 0.107 & 0.001 \\
2011 & 0.083 & 0.001 & 2018 & 0.115 & 0.001 \\
\hline
\end{tabular}

With the help of Stata16.0 software, this paper makes a spatial econometric regression test on the influencing factors of industrial GTIE in 30 provinces and cities in China. Without considering the spatial correlation, the Hausman test results are significant at the $1 \%$ level, rejecting the random effect hypothesis, so the fixed effect model is selected. Considering the heterogeneity of geographical location and economic development level of each province, this paper selects the spatiotemporal double fixed model. By comparing the results of corrected $\mathrm{R}^{2}$ and maximum likelihood estimation, spatial Dubin model (SDM) is selected for further analysis. In addition, the benchmark model adopts the adjacency weight matrix, which does not take into account the geographical distance between different provinces and cities and the spatial correlation of economic activities. Therefore, this paper further constructs the inverse distance spatial weight matrix and economic distance spatial weight matrix for robustness test. It can be seen from the estimation results in Table 3 that the coefficient symbols of all explanatory variables of SAR, SEM and SDM models have not changed, and the significance of econometric regression results has not changed. Only some spatial lag term coefficients of SDM model have become insignificant. Therefore, it can be determined that the estimation results of the benchmark model are robust.

The regression results show that the regression coefficient of enterprise scale on industrial GTIE is 0.085 , which is significant at the level of $1 \%$, indicating that the expansion of enterprise scale is conducive to the improvement of industrial GTIE. The reasons may be: on the one hand, with the expansion of enterprise scale, carrying out GTI activities can obtain higher returns to scale, which makes enterprise scale have a driving effect on technological innovation. On the other hand, the larger the scale of the enterprise, the more initial resources such as manpower and capital invested in technological innovation activities, which can better marketize the patent achievements. While obtaining greater economic value, the enterprise will increase the investment in innovation activities, forming a virtuous circle of "technology input - achievement output - economic value". In addition, the spatial lag coefficient of enterprise scale is 0.056 , which is significant at the level of $5 \%$, indicating that the expansion of enterprise scale in this region will lead to the improvement of industrial GTIE in adjacent areas. It may be because the expansion of enterprise scale will promote industrial agglomeration, attract surrounding enterprises, and accelerate the flow of talents and capital. Through the core technology spillover effect, the enterprise scale gradually forms the "regional block" distribution characteristics in China, reduces the technology exchange cost between regions, and is conducive to improving the development level of green technology.

The regression coefficient of industrial structure to industrial GTIE is -0.835 , which is significant at the level of $1 \%$, indicating that the increase of the proportion of industrial output value will reduce the industrial GTIE. Industrial structure is an important "bridge" connecting ecological construction and economic development. The characteristics of regional industrial structure determine the impact of enterprise green innovation activities on energy resources consumption and ecological environment to a certain ex- 
tent. At present, China is still dominated by the heavy industrial structure of "three high and one low", and the negative impact on the industrial GTIE continues. In addition, the spatial lag coefficient of industrial structure is 0.157 , which is significant at the level of $5 \%$, indicating that the increase in the proportion of industrial output value in this region will lead to the improvement of industrial GTIE in adjacent areas, which is similar to the conclusion previous studies. It may be because the industrial agglomeration and industrial transfer within the region lead to the concentration of high pollution and high energy consumption industries in an economic zone or economic belt, and the energy consumption and pollutant emission in the surrounding areas are significantly reduced, which promotes the industrial GTIE in the surrounding areas.

The regression coefficient of external to industrial GTIE is 0.077 , which is significant at the level of $5 \%$, indicating that the increase of total product import and export is conducive to the improvement of industrial GTIE. From the regression results, the impact of the degree of opening to the outside world on the innovation efficiency of industrial green technology supports the "pollution halo" hypothesis. The higher the degree of opening, the region will take the lead in having foreign advanced production equipment, technical level and management experience, and radiate the surrounding areas through "knowledge spillover effect" and "model effect", so as to drive the improvement of the overall green technology level. In addition, the spatial lag coefficient of the degree of opening to the outside world is -0.045 , which is significant at the level of $5 \%$, indicating that the increase of the total import and export of products in this region will reduce the industrial GTIE in adjacent areas, which is similar to the previous studies. From the perspective of the government, in order to create more employment opportunities and accelerate the marketization of R\&D achievements in areas with high openness, local governments usually adopt the way of "bottom-by-bottom competition" to attract talents and capital in adjacent areas, resulting in the decline of technical personnel and capital stock in surrounding areas and the lack of green innovation vitality. From the perspective of enterprises, industries with high energy consumption and high pollution will gradually transfer to the surrounding backward areas. These provinces and cities are already at a competitive disadvantage in foreign trade transactions, and they have to further bear the cost of environmental pollution control, resulting in the decline of the industrial GTIE.

The regression coefficient of government support on industrial GTIE is 2.755, which is significant at the level of $1 \%$, and the spatial lag coefficient is 1.712 , but it is not significant, indicating that increasing government expenditure on scientific and technological activities can promote the improvement of industrial GTIE in this region, and the impact on adjacent provinces and cities is not significant. The reasons: the impact of government support on the industrial GTIE is mainly divided into positive and negative aspects. First, reasonable government expenditure can help enterprises quickly break through the obstacles of innovation and improve the overall innovation level; Second, excessive capital investment will make local enterprises lazy to the government and reduce their enthusiasm for innovation. From the existing regression results, the positive impact of government support on the industrial GTIE is fully reflected, indicating that local governments can comprehensively promote the development of local industrial GTI from the two aspects of market regulation and government support. Adhere to market-oriented, enterprises as the main body, supplemented by government incentives, encourage enterprises to improve production efficiency and reduce pollution emissions through production technology innovation and scientific and technological R\&D innovation, so as to provide favorable conditions for improving the industrial GTIE.

The regression coefficient of environmental regulation on industrial GTIE is 2.185, which is significant at the level of $1 \%$, and the spatial lag coefficient is -0.850 , but not significant, indicating that the increase of environmental pollution control investment can effectively promote the improvement of industrial GTIE in this region, and the impact on adjacent areas is not significant. It may be because environmental regulation is 
an effective means to improve the industrial GTIE. The government often optimizes the allocation of resources through two environmental regulation methods: command control and market incentive, so as to force enterprises to innovate production equipment and upgrade industrial technology. When enterprises achieve a higher profit level and meet the government's policy requirements through low science and technology investment, environmental regulation has a "compensation effect" on technological innovation, and the efficiency of industrial green technological innovation has been improved. This result is in line with the inference of "Porter Hypothesis". It is worth noting that at present, most scholars believe that there are "U", inverted "U" and "V" nonlinear relationships between environmental regulation and GTIE. Environmental regulation can promote the improvement of GTIE only within a certain threshold. Therefore, the government should adopt appropriate environmental regulation to encourage enterprises to carry out GTI activities and give full play to the "catalyst" effect of environmental regulation.

The regression coefficient of education level on industrial GTIE is 0.065 , which is significant at the level of $10 \%$, indicating that the increase in the number of college students is conducive to the improvement of industrial GTIE in this region. There is a positive correlation between education level and human capital. The higher the regional education level, the greater the human capital stock. As the endogenous driving force of GTI, human capital can effectively promote the transformation of innovation achievements into productivity, accelerate the implementation and use of innovative technologies, and improve the efficiency of resource utilization and capital allocation. In addition, the spatial lag coefficient of education level is 0.042 , which is significant at the level of $10 \%$, indicating that the increase in the number of college students in this area will also promote the industrial GTIE in adjacent areas. The reason may be that the large-scale flow of human capital will promote information dissemination and technical knowledge exchange between regions. Through the positive spillover effect, human capital will form a "1+1>2" agglomeration effect in the region, which will improve the collective innovation consciousness and further promote the development level of industrial green technology.

Table 3 National spatial econometric regression results

\begin{tabular}{|c|c|c|c|c|c|c|c|c|c|}
\hline \multirow{2}{*}{ Variables } & \multicolumn{3}{|c|}{ Adjacency distance matrix $(W)$} & \multicolumn{3}{|c|}{ Inverse distance matrix $(D)$} & \multicolumn{3}{|c|}{ Economic distance matrix $(G)$} \\
\hline & SAR & SEM & SDM & SAR & SEM & SDM & SAR & SEM & SDM \\
\hline \multirow[t]{2}{*}{$\ln E S$} & $0.083^{*+*}$ & $0.079^{* * *}$ & $0.085^{*+*+}$ & $0.077^{* * *+}$ & $0.081^{* *+*}$ & $0.080^{+* *+*}$ & $0.066^{* *+*}$ & $0.071^{* * *}$ & $0.079^{* *+*}$ \\
\hline & $(0.45)$ & $(0.34)$ & $(0.65)$ & $(0.38)$ & $(0.55)$ & $(0.75)$ & $(0.33)$ & $(0.74)$ & $(0.64)$ \\
\hline \multirow[t]{2}{*}{$\operatorname{lnINS}$} & $-0.457^{\text {w*t+ }}$ & $-0.504^{* *+*}$ & $-0.835^{*+*+}$ & $-0.438^{*+*+}$ & $-0.511^{*+*+}$ & $-0.745^{*+*+}$ & $-0.484^{* *+4}$ & $-0.514^{n+w}$ & $-0.872^{* *}$ \\
\hline & $(-2.43)$ & $(-2.25)$ & $(-1.56)$ & $(-2.81)$ & $(-2.35)$ & $(-1.67)$ & $(-2.77)$ & $(-2.61)$ & $(-1.83)$ \\
\hline \multirow[t]{2}{*}{$\operatorname{lnOPEN}$} & $0.045^{*}$ & $0.042^{* *+}$ & $0.077^{* *}$ & $0.043^{*}$ & $0.057^{* *}$ & $0.081^{* * *}$ & $0.042^{*}$ & $0.051^{* *}$ & $0.071^{* *}$ \\
\hline & $(1.08)$ & $(1.05)$ & $(1.78)$ & $(1.18)$ & $(1.07)$ & $(1.67)$ & $(1.21)$ & $(1.14)$ & (1.84) \\
\hline \multirow[t]{2}{*}{$\ln G O V E$} & $2.563^{*+*+}$ & $2.457^{*+*+}$ & $2.755^{*+*+*}$ & $2.804^{* *+*}$ & $2.341^{* * *+}$ & $2.847^{+w+*}$ & $2.873^{* * *+}$ & $2.191^{* * * *}$ & $2.826^{* *+*}$ \\
\hline & $(6.58)$ & (6.44) & $(6.93)$ & $(6.94)$ & $(7.04)$ & $(6.85)$ & $(6.44)$ & $(6.31)$ & (6.77) \\
\hline \multirow[t]{2}{*}{$\ln E R$} & $2.238^{* *+*}$ & $2.452^{* *+*}$ & $2.185^{n+*}$ & $2.341^{* * *+}$ & $2.314^{* *}$ & $2.328^{* * *+}$ & $2.291^{* *+*}$ & $2.316^{*+*+}$ & $2.308^{* *+*}$ \\
\hline & $(7.48)$ & $(8.125)$ & $(7.32)$ & $(7.55)$ & $(7.875)$ & $(7.62)$ & $(7.33)$ & $(8.045)$ & (7.49) \\
\hline \multirow[t]{2}{*}{$\ln S T U$} & 0.032 & $0.054^{*}$ & $0.065^{*}$ & 0.043 & $0.067^{*}$ & $0.053^{*}$ & 0.049 & $0.063^{*}$ & $0.078^{*}$ \\
\hline & $(0.54)$ & $(0.61)$ & $(1.02)$ & $(0.74)$ & $(0.80)$ & $(1.22)$ & $(0.58)$ & $(0.66)$ & (0.93) \\
\hline \multirow[t]{2}{*}{$\ln E S^{*} W$} & & & $0.056^{* *}$ & & & 0.093 & & & $0.087^{* *}$ \\
\hline & & & $(1.12)$ & & & $(1.58)$ & & & (1.77) \\
\hline $\ln I N S^{*} W$ & & & $0.157^{* *}$ & & & $0.284^{*}$ & & & $0.183^{*}$ \\
\hline
\end{tabular}




\begin{tabular}{|c|c|c|c|c|c|c|c|c|c|}
\hline & & & $(0.64)$ & & & $(0.85)$ & & & $(0.74)$ \\
\hline \multirow[t]{2}{*}{$\ln O P E N^{*} W$} & & & $-0.045^{* *}$ & & & -0.038 & & & -0.051 \\
\hline & & & $(-0.72)$ & & & $(-0.65)$ & & & $(-0.87)$ \\
\hline \multirow[t]{2}{*}{$\ln G O V E^{*} W$} & & & 1.712 & & & 1.581 & & & 1.655 \\
\hline & & & (1.95) & & & $(1.85)$ & & & $(1.64)$ \\
\hline \multirow[t]{2}{*}{$\ln E R^{*} W$} & & & -0.850 & & & -0.78 & & & -0.95 \\
\hline & & & $(-1.83)$ & & & $(-1.66)$ & & & $(-1.88)$ \\
\hline \multirow[t]{2}{*}{$\operatorname{lnSTU} U^{*} W$} & & & $0.042^{*}$ & & & $0.055^{*}$ & & & 0.075 \\
\hline & & & $(0.79)$ & & & $(0.62)$ & & & $(0.81)$ \\
\hline \multirow[t]{2}{*}{$\rho$} & $0.421^{* * *+*}$ & & $0.258^{* * *+}$ & $0.538^{* *}$ & & $0.221^{*+* *+}$ & $0.607^{*}$ & & $0.240^{* *+*}$ \\
\hline & $(0.75)$ & & $(0.18)$ & $(0.69)$ & & $(0.21)$ & $(0.87)$ & & $(0.23)$ \\
\hline$R^{2}$ & 0.841 & 0.855 & 0.870 & 0.812 & 0.846 & 0.853 & 0.831 & 0.840 & 0.857 \\
\hline $\log _{-} L$ & 239.560 & 245.432 & 258.725 & 213.44 & 218.23 & 224.96 & 236.248 & 239.347 & 247.442 \\
\hline Time effect & Fixed & Fixed & Fixed & Fixed & Fixed & Fixed & Fixed & Fixed & Fixed \\
\hline $\begin{array}{c}\text { Individual } \\
\text { effect }\end{array}$ & Fixed & Fixed & Fixed & Fixed & Fixed & Fixed & Fixed & Fixed & Fixed \\
\hline $\mathrm{N}$ & 420 & 420 & 420 & 420 & 420 & 420 & 420 & 420 & 420 \\
\hline
\end{tabular}

Notes: ${ }^{* * *}$ and ${ }^{* * *}$ Denote statistical significance at the $10 \%, 5 \%$ and $1 \%$ levels, respectively. The $t$ values are in parentheses.

\subsection{Analysis of regression results in eastern, central and western Regions}

In order to further investigate the causes of the imbalance of China's industrial GTIE in different regions, this paper makes a regression test on the panel data of the eastern, central and western regions, looks for the key factors affecting different regions, and locates the weak points of industrial GTIE. Table 4 regression results show that for the eastern region, enterprise scale, government support, openness, environmental regulation and education level have a significant positive impact on the industrial GTIE, industrial structure has a significant negative impact, and the openness is not significant. Specifically, with the expansion of enterprise scale, technology intensive industries have developed rapidly, which has greatly improved the industrial GTIE. The impact of industrial structure is negative, because the positive effect brought by technological progress in the area is not enough to offset its pollution to the environment. Due to the better economic foundation, higher industrial technology intensity and more innovative technology and innovation space for enterprises in the eastern region, reasonable government expenditure and appropriate environmental regulation can promote the efficiency of local industrial GTI. The improvement of education level and import and export trade volume has largely promoted the spatial agglomeration and allocation of high-quality labor force and high-tech in the eastern region, and promoted the improvement of industrial GTIE in the region through knowledge diffusion and technology spillover effect. In addition, enterprise scale, industrial structure and education level have a significant positive impact on adjacent areas, while other factors have no significant impact on adjacent areas.

For the central region, enterprise scale, industrial structure, openness, government support and education level have a significant positive impact on the industrial GTIE, and environmental regulation has a significant negative impact. It may be because the central region is rich in energy and mineral resources, and relies on the advantages of regional natural resources to undertake and absorb the industrial transfer of developed eastern regions. On the one hand, industrial agglomeration has indeed promoted the 
rapid economic growth of the central region, accumulated original capital for technological innovation, created an investment environment to attract foreign capital and technical talents, made the central region have a certain industrial foundation, technical level and economic strength, and effectively promoted the improvement of industrial GTIE. On the other hand, due to the long-term extensive development model, the regional ecological environment is damaged, the role of regional environmental policies is not obvious, and the implementation effect of technology R\&D and energy conservation and environmental protection is not ideal. Local governments often take appropriate environmental regulation measures to reduce pollutant emissions. At this time, enterprises will unconsciously develop to "Marginalization", Hinder the improvement of industrial GTIE in this region. In addition, industrial structure and openness have a significant negative impact on adjacent areas, environmental regulation has a significant positive impact on adjacent areas, and other factors have no significant impact on adjacent areas.

For the western region, industrial structure and government support have a significant positive impact on the industrial GTIE, environmental regulation has a significant negative impact, and the other influencing factors are not significant. The reason is that one belt, one road and one belt, has been attracting more and more enterprises from home and abroad, which has stimulated the rapid economic growth in the region and accelerated regional industrial agglomeration and import and export trade. This approach will help alleviate the contradiction between economic development and ecological environment in the central region and provide preconditions for GTI activities. On the other hand, enterprises often adopt traditional production methods in the process of development and pay no attention to resource conservation, energy conservation and emission reduction and technological innovation, resulting in excessive consumption of energy and resources advantages in the region and serious damage to the ecological environment. At one time, there was an embarrassing situation of "high growth, low development and heavy pollution". In addition, the industrial structure has a significant negative impact on the adjacent areas, and the other factors have no significant impact on the adjacent areas.

Table 4 Spatial econometric regression results of Eastern, Central and Western in China

\begin{tabular}{|c|c|c|c|}
\hline Variables & Eastern Region(SDM) & Central region(SDM) & Western Region(SDM) \\
\hline $\ln E S$ & $0.079^{* * *}$ & $0.052^{* *}$ & 0.044 \\
\hline $\operatorname{lnINS}$ & $-0.754^{* *}$ & $0.748^{* *}$ & $0.875^{* * *}$ \\
\hline $\ln O P E N$ & $0.217^{* * *}$ & $0.317^{* * *}$ & 0.286 \\
\hline $\ln G O V E$ & $0.542^{* * *}$ & $0.819^{* * *}$ & $0.820^{* *}$ \\
\hline $\ln E R$ & $0.301^{* * *}$ & $-0.330^{* * *}$ & $-0.380^{* * *}$ \\
\hline $\operatorname{lnSTU}$ & $0.075^{* *}$ & $0.094^{*}$ & 0.104 \\
\hline $\ln E S^{*} W$ & $0.065^{* *}$ & 0.048 & 0.021 \\
\hline $\operatorname{lnINS} W$ & $0.235^{*}$ & $-0.204^{*}$ & $-0.670^{* *}$ \\
\hline $\ln O P E N^{*} W$ & -0.028 & $-0.118^{* *}$ & -0.175 \\
\hline $\ln G O V E^{*} W$ & 0.380 & 0.425 & 0.383 \\
\hline $\ln E R^{*} W$ & 0.112 & $0.241^{*}$ & 0.240 \\
\hline $\ln S T U^{*} W$ & $0.047^{* *}$ & 0.055 & 0.023 \\
\hline$\rho$ & $0.185^{* * *}$ & $0.147^{* * *}$ & $0.134^{* * *}$ \\
\hline$R^{2}$ & 0.822 & 0.841 & 0.897 \\
\hline $\log _{-} L$ & 283.97 & 254.69 & 268.11 \\
\hline Time effect & Fixed & Fixed & Fixed \\
\hline
\end{tabular}




$\begin{array}{cccc}\text { Individual effect } & \text { Fixed } & \text { Fixed } & \text { Fixed } \\ \mathrm{N} & 154 & 112 & 154\end{array}$

Notes: ${ }^{* *}$ and ${ }^{* *}$ Denote statistical significance at the $10 \%, 5 \%$ and $1 \%$ levels, respectively. The $t$ values are in parentheses.

\section{Conclusion}

This paper uses the super efficiency SBM model considering undesirable outputs to measure the innovation efficiency of China's industrial green technology, and the regional differences and influencing factors of industrial GTIE are analyzed in combination with Dagum Gini coefficient method and spatial econometric model. The following conclusions are drawn:

- From 2005 to 2018, China's industrial GTIE showed a relatively stable development trend, and successively experienced three stages: "stable period", "recession period" and "growth period". In terms of subregions, the change rule of industrial GTIE in China's eastern, central and western regions is similar to the overall change rule of the whole country, but the efficiency gap between the three regions is obvious, with the highest in the east, the second in the middle and the lowest in the west, and the industrial GTIE in the central and western regions is lower than the national average level.

- Dagum Gini coefficient decomposition shows that, the overall difference of industrial GTIE showed a fluctuating downward trend from 2005 to 2018. The between-regional differences are the main factors leading to the overall differences, followed by intra-regional differences, and finally the intensity of transvariation. Among the regional differences, the eastern region and the western region have the largest difference in industrial GTIE, followed by the east central region. There is an unbalanced pattern of industrial GTIE among the three regions. In terms of regional internal differences, the changes of internal differences in the eastern region are relatively stable, the internal differences in the central region are relatively low and show an inverted "U" trend, and the internal differences in the western region change greatly and show a fluctuating downward trend.

- Enterprise scale and education level can promote the improvement of China's industrial GTIE, and can promote the development of industrial GTIE in adjacent areas. The degree of government support and environmental regulation also have a positive impact on the industrial GTIE, but the spatial spillover effect is not significant. Industrial structure can inhibit the industrial GTIE, but can promote the industrial GTIE in adjacent areas. The degree of openness has a positive impact on the industrial GTIE, but it has an inhibitory effect on the industrial GTIE in adjacent areas. In terms of region, the enterprise scale, government support, openness, environmental regulation and education level in the eastern region have a significant positive impact on the industrial GTIE, a significant negative impact on the industrial structure, and the openness is not significant. The enterprise scale, industrial structure, openness, government support and education level in the central region have a significant positive impact on the industrial GTIE and a significant negative impact on environmental regulation. The industrial structure and government support in the western region have a significant positive impact on the industrial GTIE, a significant negative impact on environmental regulation, and the other influencing factors are not significant. In addition, various influencing factors have different degrees of spatial spillover effects on different regions.

According to the above research conclusions, the followings practical significance are obtained.

- For the whole China, while improving the industrial GTIE, actively seek the linkage development between regions, gradually build a phased and deep-level regional innovation development plan in combination with the characteristics of regional economic and social development, effectively reduce the institutional transaction cost, and strive 
to break through the structural contradictions and institutional obstacles in the process of regional linkage innovation. Relying on the resource advantages of Shanxi, Henan and other heavy industrial provinces, promote industrial integration with coal and steel, and develop and research new technologies focusing on new utilization of coal and new materials.

- For the eastern region, the leading role of industrial parks and industrial ecological parks in promoting green and ecological industry is highlighted, the site selection and planning of the park are highly valued, the high starting point planning, high-level design and high standard construction are adhered to, and the industrial park is committed to integrating product $R \& D$, technology upgrading new urban functional complex integrating education and training.

- For the central and western regions, the government should consider the enthusiasm of industrial enterprises in the process of R\&D and innovation, establish and improve corresponding policies and measures, improve the construction of industrial infrastructure, and create a more suitable innovation environment, such as implementing innovation subsidies, green consumption and talent policies to form industrial agglomeration and technology agglomeration, So as to promote the improvement of GTIE.

Author Contributions: This paper is a collaborative work of the all the authors. Writing Original Draft Preparation, Visualization and Methodology Pengzhen Liu; Formal Analysis, Funding Acquisition, Writing-Review, Supervision Liyuan Zhang. All authors have read and agreed to the published version of the manuscript.

Funding: This research was funded by National Social Science Foundation, grant number 19BJY085.

Institutional Review Board Statement: Not applicable.

Informed Consent Statement: Not applicable.

Data Availability Statement: The data presented in this study are available on request from the first and corresponding authors.

Conflicts of Interest: The authors declare no conflict of interest

\section{References}

1. Shao, Shuai, Zhenbing Yang, Lili Yang, and Shuang Ma. "Can China's Energy Intensity Constraint Policy Promote Total Factor Energy Efficiency? Evidence from the Industrial Sector." The Energy Journal 40, no. 4 (2019).

2. Shen, Chen, Shenglan Li, Xiaopeng Wang, and Zhongju Liao. "The Effect of Environmental Policy Tools on Regional Green Innovation: Evidence from China." Journal of Cleaner Production 254 (2020): 120122.

3. Mao, Wenxin, Wenping Wang, and Huifang Sun. "Driving Patterns of Industrial Green Transformation: A Multiple Regions Case Learning from China." Science of The Total Environment 697 (2019): 134134.

4. Fussler, Claude, and Peter James. Driving Eco-Innovation: A Breakthrough Discipline for Innovation and Sustainability: Financial Times/Prentice Hall, 1996.

5. Chen, Xiaohong, Na Yi, Lu Zhang, and Dayuan Li. "Does Institutional Pressure Foster Corporate Green Innovation? Evidence from China's Top 100 Companies." Journal of Cleaner Production 188 (2018): 304-11.

6. Schiederig, Tim, Frank Tietze, and Cornelius Herstatt. "Green Innovation in Technology and Innovation Management-an Exploratory Literature Review." REd Management 42, no. 2 (2012): 180-92.

7. Xie, Xuemei, Jiage Huo, and Hailiang Zou. "Green Process Innovation, Green Product Innovation, and Corporate Financial Performance: A Content Analysis Method." Journal of business research 101 (2019): 697-706.

8. Marra, Alessandro, Paola Antonelli, and Cesare Pozzi. "Emerging Green-Tech Specializations and Clusters-a Network Analysis on Technological Innovation at the Metropolitan Level." Renewable and Sustainable Energy Reviews 67 (2017): 1037-46.

9. Luo, Qiaoling, Chenglin Miao, Liyan Sun, Xiaona Meng, and Mengmeng Duan. "Efficiency Evaluation of Green Technology Innovation of China's Strategic Emerging Industries: An Empirical Analysis Based on Malmquist-Data Envelopment Analysis Index." Journal of Cleaner Production 238 (2019): 117782.

10. Li, Tuochen, Lei Liang, and Dongri Han. "Research on the Efficiency of Green Technology Innovation in China's Provincial High-End Manufacturing Industry Based on the Raga-Pp-Sfa Model." Mathematical Problems in Engineering 2018 (2018). 
11. Xu, Shuoran, Ting $\mathrm{Wu}$, and Yao Zhang. "The Spatial-Temporal Variation and Convergence of Green Innovation Efficiency in the Yangtze River Economic Belt in China." Environmental Science and Pollution Research 27, no. 21 (2020): 26868-81.

12. Liu, Chunyang, Xingyu Gao, Wanli Ma, and Xiangtuo Chen. "Research on Regional Differences and Influencing Factors of Green Technology Innovation Efficiency of China's High-Tech Industry." Journal of computational and applied mathematics 369 (2020): 112597.

13. Wang, Shuai, Jin Fan, Dingtao Zhao, and Shanyong Wang. "Regional Innovation Environment and Innovation Efficiency: The Chinese Case." Technology Analysis E Strategic Management 28, no. 4 (2016): 396-410.

14. Yangjun, Ren, and Wang Chuanxu. "Research on the Regional Difference and Spatial Effect of Green Innovation Efficiency of Industrial Enterprises in China." Revista Ibérica de Sistemas e Tecnologias de Informação, no. E10 (2016): 373.

15. Feng, Zhijun. "Research on Industrial Enterprises' Green Innovation Efficiency in China - - - Based on Provincial Data by a Dea-Sbm Approach." Forum on Science and Technology in China, no. 02 (2013): 82-88 (in Chinese).

16. Li, Jing, and YuanXin Du. "Spatial Effect of Environmental Regulation on Green Innovation Efficiency: Evidence from Prefectural-Level Cities in China." Journal of Cleaner Production 286 (2021): 125032.

17. Ren, Yao, Chonghuai Niu, Tong Niu, and Xilong Yao. "Theoretical Model and Empirical Research on Green Innovation Efficiency." Management World, no. 07 (2014): 176-77.

18. Wang, Haoran, Herui Cui, and Qiaozhi Zhao. "Effect of Green Technology Innovation on Green Total Factor Productivity in China: Evidence from Spatial Durbin Model Analysis." Journal of Cleaner Production 288 (2021): 125624.

19. Shi, Yucheng, Weiguo He, Jian Zhao, Aoyu Hu, Jingna Pan, Haizheng Wang, and Honglu Zhu. "Expected Output Calculation Based on Inverse Distance Weighting and Its Application in Anomaly Detection of Distributed Photovoltaic Power Stations." Journal of Cleaner Production 253 (2020): 119965.

20. Han, Xiuyan, Tao Sun, and Tianyi Cao. "Study on Environmental Pollution Loss Measurement Method of Waste Gas Emits in Nanjing Mv Industrial Park." Environmental Science and Pollution Research 27, no. 14 (2020): $16539-53$.

21. Miao, Chenglin, Debin Fang, Liyan Sun, and Qiaoling Luo. "Natural Resources Utilization Efficiency under the Influence of Green Technological Innovation." Resources, Conservation and Recycling 126 (2017): 153-61.

22. Guo, Yingyuan, Xingneng Xia, Sheng Zhang, and Danping Zhang. "Environmental Regulation, Government R\&D Funding and Green Technology Innovation: Evidence from China Provincial Data." Sustainability 10, no. 4 (2018): 940.

23. Wang, Qinhua, Jiansheng Qu, Bao Wang, Penglong Wang, and Taibao Yang. "Green Technology Innovation Development in China in 1990-2015." Science of The Total Environment 696 (2019): 134008.

24. Zhang, Dongyang, and Samuel A Vigne. "How Does Innovation Efficiency Contribute to Green Productivity? A Financial Constraint Perspective." Journal of Cleaner Production 280 (2021): 124000.

25. Fan, Fei, Huan Lian, Xiaoyang Liu, and Xueli Wang. "Can Environmental Regulation Promote Urban Green Innovation Efficiency? An Empirical Study Based on Chinese Cities." Journal of Cleaner Production 287 (2021): 125060.

26. Zhang, Jingxiao, You Ouyang, Pablo Ballesteros-Pérez, Hui Li, Simon P Philbin, Zhaoling Li, and Martin Skitmore. "Understanding the Impact of Environmental Regulations on Green Technology Innovation Efficiency in the Construction Industry." Sustainable Cities and Society 65 (2021): 102647.

27. Du, Kerui, Yuanyuan Cheng, and Xin Yao. "Environmental Regulation, Green Technology Innovation, and Industrial Structure Upgrading: The Road to the Green Transformation of Chinese Cities." Energy Economics 98 (2021): 105247.

28. Luo, Xiao, and Weiye Zhang. "Green Innovation Efficiency: A Threshold Effect of Research and Development." Clean Technologies and Environmental Policy 23, no. 1 (2021): 285-98.

29. Zhang, Jingxiao, Le Kang, Hui Li, Pablo Ballesteros-Pérez, Martin Skitmore, and Jian Zuo. "The Impact of Environmental Regulations on Urban Green Innovation Efficiency: The Case of Xi'an." Sustainable Cities and Society 57 (2020): 102123.

30. Wang, Lu, Wenzhong Ye, and Lingming Chen. "Research on Green Innovation of the Great Changsha-Zhuzhou-Xiangtan City Group Based on Network." Land 10, no. 11 (2021): 1198.

31. Liu, Jia, Qiuyue Song, Ning Liu, and Christina Gengging Chi. "Threshold Effects of Tourism Agglomeration on the Green Innovation Efficiency of China's Tourism Industry." Chinese Journal of Population Resources and Environment 16, no. 3 (2018): 277-86. 
32. Wang, Qiao, Shuo She, and Jingjing Zeng. "Action Mechanism and Effect Identification of National High Tech Area to Improve Urban Green Innovation Efficiency -- a Test Based on Difference in Difference Method." China Population, Resources and Environment 30, no. 02 (2020): 129-37 (in Chinese).

33. Zeng, Jin-ye. "An Research on the Influence Factors of China's High-Tech Industry's R\&D Activities Efficiency." Paper presented at the 2009 International Conference on Management Science and Engineering 2009.

34. Alarcón, Silverio, and Mercedes Sánchez. "External and Internal R\&D, Capital Investment and Business Performance in the Spanish Agri - Food Industry." Journal of Agricultural Economics 64, no. 3 (2013): 654-75.

35. Berlemann, Michael, and Jan-Erik Wesselhöft. "Estimating Aggregate Capital Stocks Using the Perpetual Inventory Method." Review of Economics 65, no. 1 (2014): 1-34.

36. Li, Yuting, and Zhiyong Zhu. "Institutional Supply and Green Innovation Efficiency in China." Journal of Beijing Institute of Technology(Social Sciences Edition) 21, no. 01 (2019): 50-58 (in Chinese).

37. Cheng, Qiongwen, Xianxiang He, and Baosheng Li. "Green Technology Innovation Efficiency and Its Influencing Factors -an Empirical Study Based on 35 Industrial Industries in China." Journal of Central South University(Social Sciences) 26, no. 02 (2020): 97-107 (in Chinese).

38. de Medeiros, Janine Fleith, Gabriel Vidor, and José Luís Duarte Ribeiro. "Driving Factors for the Success of the Green Innovation Market: A Relationship System Proposal." Journal of business ethics 147, no. 2 (2018): 327-41.

39. Ambec, Stefan, Mark A Cohen, Stewart Elgie, and Paul Lanoie. "The Porter Hypothesis at 20: Can Environmental Regulation Enhance Innovation and Competitiveness?" Review of environmental economics and policy 7, no. 1 (2013): 2-22.

40. Lerman, Robert I, and Shlomo Yitzhaki. "Improving the Accuracy of Estimates of Gini Coefficients." Journal of econometrics 42, no. 1 (1989): 43-47.

41. LeSage, James P, and R Kelley Pace. "The Biggest Myth in Spatial Econometrics." Econometrics 2, no. 4 (2014): 217-49. 